\title{
IoT Based Wearable Device for Enhancing Holistic Students Evolution
}

\author{
Mr. J. Dani Reagan Vivek ${ }^{1}$, S. Lakshmanan ${ }^{2}$, S. Karthik ${ }^{3}$ \\ Assistant Professor, ECE Department, Mepco Schlenk Engineering College, Sivakasi, India ${ }^{1}$ \\ Student, ECE Department, Mepco Schlenk Engineering College, Sivakasi, India ${ }^{2}$ \\ Student, ECE Department, Mepco Schlenk Engineering College, Sivakasi, India ${ }^{3}$
}

\begin{abstract}
Holistic education is a philosophy of education, based on the premise that each person finds identity, meaning, and purpose in life through connections to the community. The major aim of our proposal is to introduce the IoT concept in schooling, for enhancing the performance metrics of young wards, as well as making the learning process enthusiastic and amusing. At the same time, it promises to reduce the burden of a tutor, by ensuring that the performance acquisition \& analysis of students is automated, by means of IoT based wearable devices. The tutor will be provided with the ease of identifying a child, who finds difficulty in the learning process and steps regarding knowledge improvement can be taken. It aims to nurture the self confidence in young learners, who have not responded well to the traditional methodology. The children will be entrusted with the art of learning a foreign language, with the help of IoT enabled objects and devices, through the task-based learning approach.
\end{abstract}

Keywords: IoT, RFID tags, Task based learning, Wearable device.

\section{INTRODUCTION}

Nowadays, a large number of language tutors are expressing their interest over task based learning approach. The usage of wearable devices and sensor based objects, for the creation of a IoT based learning environment has been proposed by Elena de la Guia, Vicente Lopez Camacho and et all[1]. Smart phones have been used as a wearable device, and the entire classroom has been divided into context based sectors, based on the task allotted to the students. Predetermined tasks are being written into the NFC tags, by means of NFC writer tool by the tutor. The students do scan the NFC Tags, and the performance analysis of individual wards are stored in a centralized server, in a Wi-Fi enabled environment. iBeacon has been used for notifying the students, who were searching for their tasks in the wrong sector. An individual as well as a group feedback would be provided by the centralized server. This approach has enhanced the collaborative learning among the young wards.

An ubiquitous system of robot based learning approach has been proposed by Nian-Shing Chen, I-Chun Hung, Chun-Wang Wei in [2],[3]. In this approach, an individual robot has been deployed for each student. The Robot provides the up-to-date learning materials, and constantly monitors the student's activity. Based upon the interactions with the robot, it identifies the potential field of interest of the students, and enhances the learning effectiveness of the students. u-ONE software and API tool has been used for the creation of an interactive learning environment, and to update the content material for learning.

A Teachable Agent based learning system has been proposed in [4]. A teachable agent, accepts the inputs from students and creates concept maps, that connect the nodes with the relational links. It enhances the reasoning ability among the learners, by means of concept maps. The young wards do create their own hierarchical maps with the help of TA software.

A prototype named Linked Open Data Learning was presented on [5], which employs semantic web technologies for enhancing the learning content.

\section{TASK BASED LANGUAGE LEARNING}

In this section we discuss our proposal, fundamental requirements for task based language learning and the system architecture.

\section{A. Proposed Model}

Our proposal consists of several wireless client module and a single server module. Every student will be provided with a wireless client module. The server will automate the process of assigning mutually exclusive tasks to every individual and perform data acquisition \& analysis, regarding the number of tasks completed by the students.

\section{B. Classroom Environment}

Education should help an individual to evolve better. In this case, involving children, the class room is made interactive by arranging tables in designated area, attractive stickers. Since the activities are performed in different areas of the class, it is important to allocate areas so that the students can learn without any distractions.

Our proposal aims to visualize a collaborative learning scenario among the young learners. A change in the learning scenario could only be effective, if it is to target 
the society right from its infant stage i.e. young learners/wards. These young learners become absolutely conscious of their actions, do learn to understand and reason right from their infancy.

\section{Task based Learning}

In the perspective of education, a task can be considered as an activity, to be performed by the students, under the supervision of their mentor. The tutor here plays the role of a mentor, whereas the young wards take up their roles as a student. The children do feel passionate, when they were asked to execute a task rather than listening to lectures, as in traditional methodology. Tasks may be partitioned as

- Information tasks- tasks which require the exchange of information amongst young wards, thus enabling a collaborative learning environment.

- Opinion tasks- tasks which focuses to bring out the personal preferences, feelings or attitudes.

- Reasoning tasks- which aims to nurture reasoning ability among young learners, by making them to infer.

D. Wireless client module

The wireless client module consists of an processor, SD card module, a speaker, Rfid reader, Oled display and a Nodemcu esp8266 wifi module. For processing and for speaker output, Arduino has been used. Rfid reader has been used to scan the RFID tags. The wearable device makes use of a Oled display for conveying the message, to the young wards. Fig. 1 depicts the block diagram of Wearable device.

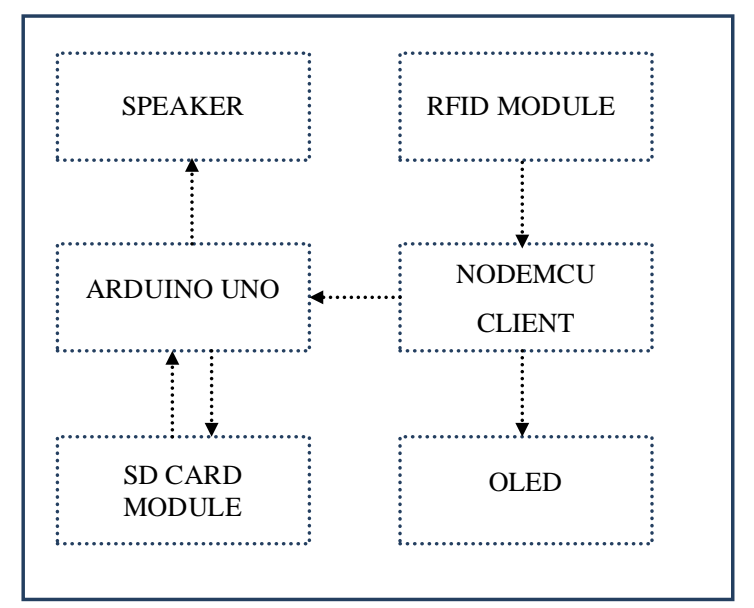

Fig.1 Wearable Device Block Diagram

All the audio will be stored in the SD module, which is attached with a speaker through the Arduino. Nodemcu module is made to operate under client mode, for the wearable module unit.

\section{E. Centralized Server}

We made use of Nodemcu module for creating an interactive server, to communicate with the wearable devices. Fig. 2 depicts the centralized server block diagram. The Nodemcu module operates under AP mode, enable it to connect with other devices. The Nodemcu module operating under AP mode creates a local network . The clients gets connected to the server module. IP addresses are assigned sequentially.

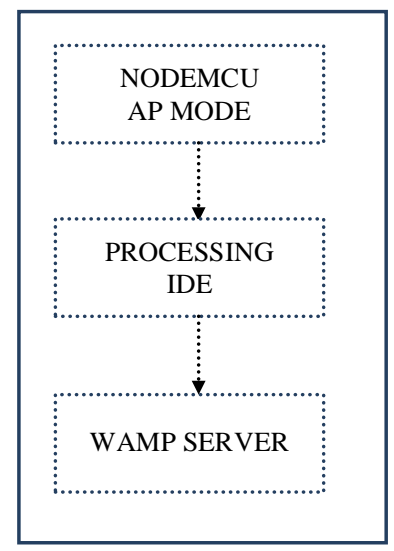

Fig.2 .Centralized Server Block Diagram

\section{WORKING}

\section{A. Client}

The client scans for the access point and gets connected to the centralized server. The IP address are allocated sequentially. The confirmation is displayed in the Oled display. The task numbers are unique and sent from the server. Based on the task number, the tasks that are ascertained with the student is displayed on the Oled module. Student starts to search and scan the objects with the Rfid reader. Fig.3. depicts some of the Rfid tags displaying tasks. The Rfid number is verified with the loaded task number and UID of the tag to ensure the integrity of correct scanning. If matched, a command to play an corresponding audio file will be sent to the Arduino, else an error message is displayed. On reception of the message from Nodemcu client module, Arduino will initialize the SD module \& send appropriate commands to play audio files in two different languages. The first language can be of the choice of their mother-tongue and the second choice can be any one amongst the foreign language. Here, we have chosen English and French.

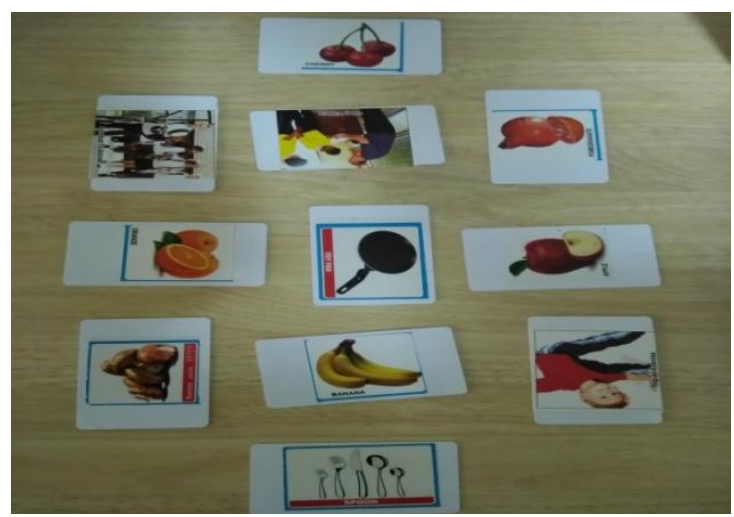

Fig.3.Rfid Tags displaying tasks. 


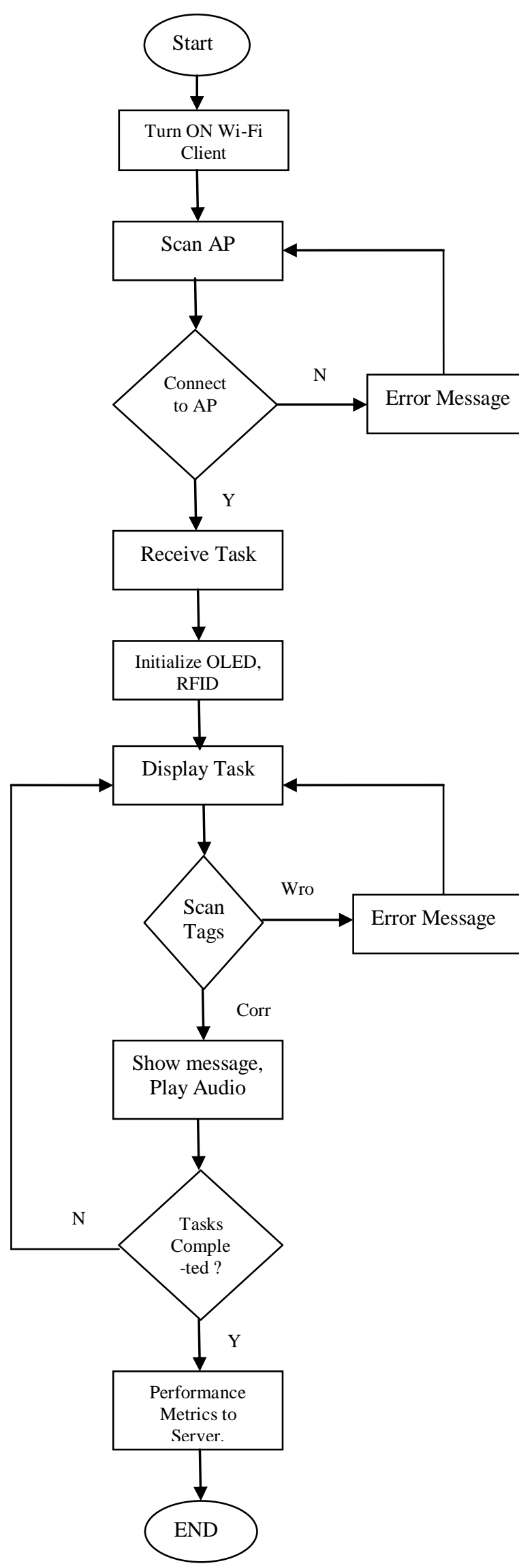

Fig.4 Flow chart depicting the algorithm
For an instance, assume that a student is ascertained with the information task from the server. It asks him to perform a sequence of subtasks in relation with one another. Let us assume that subtasks are concerned about preparing a daily routine for a student. The following sequence of tasks can be considered as an example for Information Tasks.

- Wake up at 6a.m in the morning.

- Brush your teeth.

- Have your breakfast.

- Leave for school by the van.

- Reach your school and greet your tutor.

The student will be asked to search for a particular Rfid tag, which contains these tasks in visuals i.e. stickers. The algorithm is depicted in the flow chart Fig 4. By performing these sequence of tasks, a student will be able to clearly visualize a picture for his/her daily routine. At the same time, he/she enjoys the pleasure of learning an additional language.

\section{B. Server}

- The server side includes the WampServer, and a Nodemcu module.

- Nodemcu module is made to operate under the AP mode.

- The Wampserver allows to create web application with various databases which includes Apache2, PHP, MySQL.

- With the WampServer Apache2 and MySQL services can be managed. Access logs are maintained and the alias can be changed.

After completing the task, the wireless client modules are greeted with the completion message. Duration to complete the task and attempts made to complete are sent to the Server module. For the visual presentation, the processing IDE software is used. From Processing IDE, the incoming data are uploaded to the WampServer database.

The performance is analyzed from the data sent by the wireless client modules. Charts and graphs are plotted from the data obtained. If the performance in the particular sector is not as expected, a feedback message is sent to the student that he/she should repeat the tasks.

Tutor can make use of the charts and graphs to analyze the sector where the students are well versed and where they are lagging.

\section{HARDWARE AND IMPLEMENTATION}

Bearing in mind, task based approach, this section describes how we deployed the objects and later the results are discussed.

\section{A. Pre Task}

The tutor has to identify the Rfid number and load the uid number into the wearable wireless client modules. The 
tasks are prepared by the tutor and loaded in the server. For displaying the messages and tasks, received from the The tasks uploaded can be modified and transmitted based on the performance of the student.

\section{B. Hardware Setup}

For the purpose of communicating with the SD module, Arduino UNO module, has been used. It works on a $5 \mathrm{v}$ logic and has 14 digital I/O pins \& 6 Analog pins. Arduino UNO communicates via SPI to the SD module. It has single UART on the pins $0 \& 1$. The Micro SD card module supports up to 4GB SD card, in which the audio files are stored. It works on a standard SPI Interface \& has a level conversion circuitry. For the purpose of scanning Rfid tags, Rfid Module operating at $13.56 \mathrm{MHz}$ frequency, has been used. It works on $3.3 \mathrm{v}$ logic and makes use of SPI for contactless communication with the wireless Nodemcu Client module.

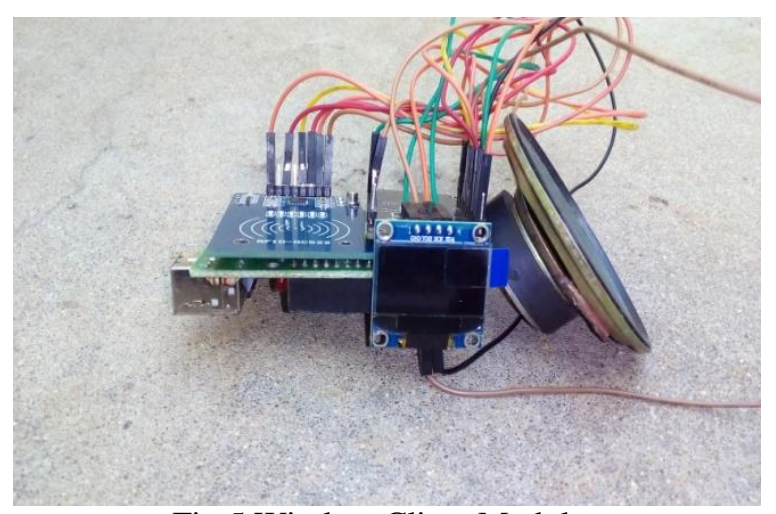

Fig.5.Wireless Client Module.

Fig.5 depicts the wireless client module, which has been used as a wearable device unit. For the purpose of establishing a wireless mode of connectivity between the tutor and students, Nodemcu module has been used. Nodemcu module, which has DNS support, has 4 modes of operation. They are

- AP Mode, which creates its own network, where other devices can join.

- Station Mode, where it joins an already available network.

- Both AP \& Station Mode, where it has the capability to join an existing network \& create it's own.

- Wi-Fi Off Mode.

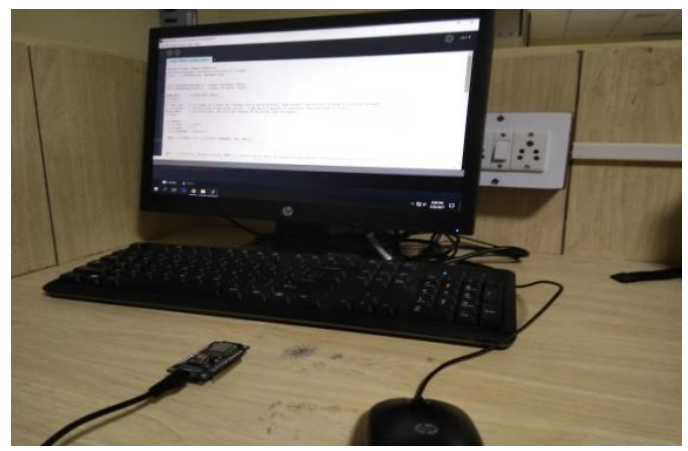

Fig.6.Centralized Server. wireless server module, Oled module has been used. Oled module supports $\mathrm{I} 2 \mathrm{C}$ mode of communication \& has ultra low power consumption of only $0.08 \mathrm{~W}$ when fully lit. Has the additional functionality of displaying images, adjusting brightness \& contrast. Speaker with a specification of $70 \mathrm{~mm}$ diameter, $8 \mathrm{~W}$ operating power and $8 \mathrm{ohm}$ resistance were used.Fig.6. depicts the Centralized server unit.

\section{Software Setup}

Arduino IDE, a open source software, has been used to program the Nodemcu and Arduino UNO modules. The environment is based on Java and Processing and other open source platforms. Processing IDE, a visual graphic user interface has been used to grab serial data from the wireless Nodemcu server module and to plot graphs and charts. At the same time, it transfers the data to the WampServer database. WampServer, a software stack for windows OS, consists of Apache Webserver, OpenSSL for SSL support, has been used to store the performance metrics of individual young wards.

\section{RESULTS \& OUTPUT}

A new model of classroom setup was made, the performance metrics of individual students are analyzed, and the data was stored in a WampServer database. Nodemcu modules were operated under various modes and the wireless mode of connectivity was established among the devices. The entire embedded system makes a way of ease for the tutor to analyze the performance metrics of individual wards. Charts and graphs were plotted from the metrics of individual students. Each and every student is greeted with a feedback about his performance. The system aims to identify a student who finds difficulty in understanding the subject. Special attention can be paid to students who finds difficulty in the learning process. Fig.6. depicts the performance analysis of a sample student.

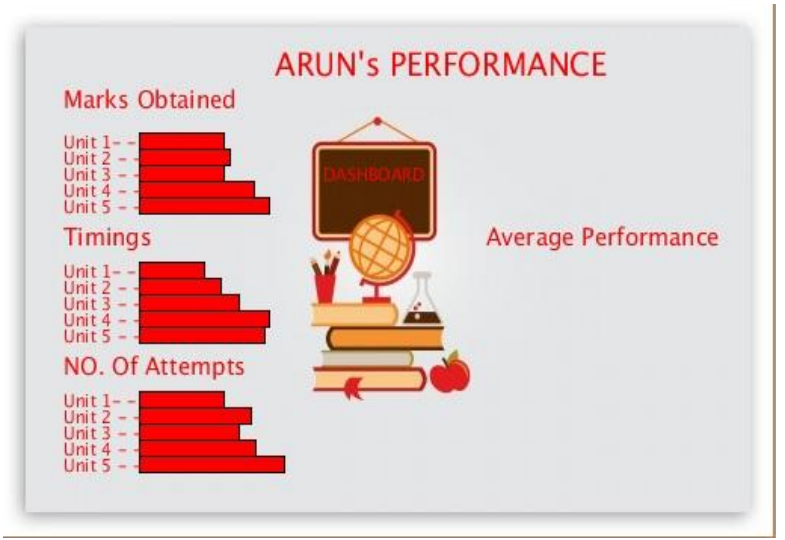

Fig.6.Performance Analysis of a sample student.

Fig.7 depicts the sample data of individual students stored in WampServer database. The data can be used for future reference and a cumulative analysis of all the data can be 
done. The tutor can retrieve the data from the database and can analyze the student's performance.

\begin{tabular}{|c|c|c|c|}
\hline f name & I mark & | time & I attempts \\
\hline $\begin{array}{l}\text { Arun } \\
\text { john } \\
\text { Karthik } \\
\text { Dhejo } \\
\text { Ragul }\end{array}$ & $\begin{array}{l}90 \\
88 \\
83 \\
98 \\
45\end{array}$ & $\begin{array}{r}134 \\
7 \\
34 \\
45 \\
231\end{array}$ & $\begin{array}{r}24 \\
2 \\
12 \\
5 \\
34\end{array}$ \\
\hline
\end{tabular}

Fig.7. Data stored in WampServer.

\section{FUTURE SCOPE}

Further, the student's heart rate and the atmosphere where they are working can be monitored from the wireless client module and sent to the server module. The tutor can precisely monitor the student. This approach can be extended for playing games among themselves. By setting up the wireless client module, the students can decide whether the communication has to be made with the server module or with other wireless client module. For performing the tutor ascertained task, the student communicate with the server module and the results will be updated. whereas while playing games, apart from the ascertained task, the communication can be established within the wireless client modules.

\section{REFERENCES}

[1] Elena de la Guia, Vicente L_opez Camacho, Luis OrozcoBarbosa, Victor M. Brea Lujan, Vıctor M. R. Penichet, and Marıa Lozano Perez, "Introducing Iot and Wearable Technologies into Task-based Language Learning for Young Children",IEEE Tranactions on Learning Technologies, vol. 9, No.4, OctoberDecember,2016, pp. 366-378.

[2] Nian-Shing Chen, I-Chun Hung, Chun-Wang Wei, "Developing Ubiquitous Learning System with Robots for Children's Learning", IEEE International Conference on Digital Game and Intelligent Toy Enhanced Learning, 2010, pp.62-68.

[3] W.H. Ko, S.M. Lee, K.T. Nam, W.H. Shon and S.H. Ji, "Design of a Personalized R-Learning System for Children ",The 2010 IEEE/RSJ International Conference on Intelligent Robots and Systems, October 2010, Taipei, Taiwan, pp.3893-3898.

[4] Doris B. Chin, Ilsa M. Dohmen, and Daniel L. Schwartz, "Young Children Can Learn Scientific Reasoning with Teachable Agents", IEEE Transactions on Learning Technologies, vol. 6, No.3, JulySeptember, 2013,pp.248-257.

[5] Herminio Garc'ia-Gonz' alez, Jos'e Emilio Labra Gayo, and MPuerto Paule-Ruiz, "Enhancing e-Learning content by using Semantic Web technologies", DOI 10.1109/TLT.2016.2629475, IEEETransactions on Learning Technologies. 